\title{
Lógicas mediales y narrativas: transmedialización de las narrativas sobre el narcotráfico en Colombia*
}

Medial and

Narrative Logics:

Transmedialization of

Narratives about Drug

Trafficking in Colombia

\section{Lógicas mediáticas}

e narrativas:

transmedialização

das narrativas sobre

o narcotráfico na

Colômbia
Para citar este artículo

Forero Medina, N. (2019). Lógicas mediales y narrativas: transmedialización de las narrativas sobre el narcotráfico en Colombia. Folios, 49, 137-147. doi: 10.17227/Folios.49-9400

Nelson Camilo Forero Medina** Orcid: https://orcid.org/0000-0002-0277-2587

* El presente texto se deriva de mi investigación de doctorado que desarrollo con el patrocinio de Colciencias. Quisiera también agradecer a Gabriela Trompetero por sus correcciones y valiosos comentarios.

* Máster en Inter-American Studies en la Universidad de Bielefeld. Estudiante del doctorado Estudios Inter-Americanos en la misma universidad. Docente de la misma institución. Correo electrónico: forero_medina@uni_bielefeld.de

Artículo recibido $28 \cdot 02 \cdot 2017$

Artículo aprobado $20 \cdot 06 \cdot 2018$ 


\section{Resumen}

En el presente texto se busca mostrar las diferentes lógicas o gramáticas que existen entre diferentes medios, a saber, el libro, la televisión y el streaming. Con este objetivo, se evalúan tres productos mediales que corresponden a un mismo tema: las narrativas sobre la violencia del narcotráfico en Colombia en los años ochenta. Así, se analiza el libro de Alonso Salazar, La parábola de Pablo: auge y caída de un gran capo colombiano (2001); El patrón del mal, de Caracol Televisión (Moreno y Mora, 2012), y la serie Narcos (Bernard, Brancato y Doug, 2015), de la cadena de streaming Netflix. El texto se divide en dos partes: la primera analiza las diferencias puramente mediales entre el libro y los medios audivisuales. Aí mismo, se desarrolla una descripción de los fenómenos de transmedialización. La segunda se enfoca en los cambios que se producen en los contenidos al ser transmedializados. A diferencia de la primera parte, este capítulo aborda las diferencias discursivas y de recepción que se crean a partir de la adaptación de la historia del patrón del mal por parte de la plataforma Netflix.

\section{Palabras clave}

lógicas mediales; narcotráfico; escrituralidad; video; transmedialización

\section{Abstract}

The purpose of this paper is to show the different logics or grammars existing between different media, namely books, television and streaming. To that end, we evaluate three media products about the same topic: narratives on drug violence in Colombia during the eighties. As a result, we analyze Alonso Salazar's book, La parábola de Pablo: auge y caída de un gran capo colombiano (2001); El patrón del mal, by Caracol Televisión (Moreno \& Mora, 2012), and the series Narcos (Bernard, Brancato, \& Doug, 2015), by streaming platform, Netflix. The text is divided in two sections: the first one analyzes the purely medial differences between the book and audiovisual media and describes the transmedialization phenomena. The second section focuses on the changes in contents when they are transmedialized. Unlike the first section, this one addresses the discursive and reception differences generated from the adaptation of the drug lord's story by the Netflix platform.

\section{Keywords}

medial logics; drug trafficking; scripturality; video; transmedialization

\section{Resumo}

No presente texto visamos apresentar as diversas lógicas ou gramáticas que existem entre diversos médios, a saber, o livro, a televisão e o streaming. Com esse objetivo, avaliamos três produtos mediais que correspondem a um tema só: as narrativas sobre a violência do narcotráfico na Colômbia nos anos oitenta. Assim, analisamos o livro de Alonso Salazar, La parábola de Pablo: auge y caída de un gran capo colombiano (2001); El patrón del mal, de Caracol Televisión (Moreno y Mora, 2012), e a série Narcos (Bernard, Brancato y Doug, 2015), da plataforma de streaming Netflix. 0 texto está dividido em duas partes: a primeira analisa as diferenças exclusivamente mediais entre o livro e os médios audiovisuais. A segunda, está focada nas mudanças produzidas nos conteúdos ao ser transmedializados. Diferente da primeira parte, este capítulo aborda as diferenças discursivas e de recepção creadas a partir da adaptação da história do patrón del mal por parte da plataforma Netflix.

\section{Palavras-chave}

lógicas mediáticas; narcotráfico; escrituralidade; video; transmedialização 


\section{Introducción}

La transmedialización no es un proceso nuevo. Ya el paso de relatos orales a escritos implicaba un cambio de medio que traía a su vez una transformación en las condiciones epistemológicas necesarias para la experiencia del sujeto receptor, las condiciones tecnológicas para su transmisión y reproducción, y finalmente cambios en el relato mismo. Estas transformaciones, sin embargo, no se daban con la celeridad que imprimen los nuevos medios. Internet, en especial, ha producido cambios tan rápidos como profundos en la comunicación, que hacen evidentes para una misma generación en un muy corto tiempo el rol central de los medios en la experiencia comunicativa y las construcciones sociales que de ella se derivan.

Si bien los medios cumplen un rol vital en la transformación de los contenidos, aquellos no dejan de reaccionar a otros sistemas como el económico, cultural, político, etc. De allí que los contenidos transmedializados también respondan al horizonte de expectativas del público al cual se le va a ofrecer el producto, así como a las características propias del medio y su relación con la sociedad. Así, en el presente texto se pretende dar cuenta de los cambios epistemológicos, tecnológicos y culturales que implican la transmedialización. De este modo, el texto abordará dos grandes temas: la transmedialización desde los medios mismos y los cambios narrativos que se imprimen en esa transformación. Para este objetivo se usarán los relatos basados en la violencia del narcotráfico en la Colombia de los años 1980. Se analizarán tres productos mediales de alto impacto en cuanto a su divulgación, a saber: el libro de Alonso Salazar, La parábola de Pablo: auge y caída de un gran capo colombiano (2001); El patrón del mal, de Caracol Televisión (Moreno y Mora, 2012), y la serie Narcos (Bernard, Brancato y Doug, 2015), de la cadena de streaming Netflix.

\section{Transmedialización}

Con transmedialización se hace referencia a la transferencia de un contenido de un medio a otro. Debido a cuestiones de espacio, no podré describir a detalle el debate sobre la definición misma de medio. Así, se entenderá por medio todos aquellos sistemas que median necesariamente una acción, ya sea entre los sujetos, los sujetos y su medio ambiente, o entre sistemas o sociedades. Si bien la definición parece redundante, en el sentido de afirmar que los medios median, con ello se quiere agrupar un número amplio de funciones y características que estos cumplen, y que al hacer una de estas características predominante, muchos de los rasgos de los medios se perderían. Dentro de estas características y funciones se pueden nombrar, entre otras, la transmisión, la creación de nuevas condiciones epistemológicas, objetos de poder, etc. (Krämer, 1998). Es decir, todas estas funciones son desarrolladas por los medios, sin que los sujetos puedan desarrollarlas por sí mismos. Para ejecutar una acción $\mathrm{X}$, por ejemplo, es necesario un medio $\mathrm{Y}$. En este sentido, los medios median necesariamente.

De esta manera, al afirmar la existencia de una transmedilización, lo que se está queriendo decir es que una acción $\mathrm{X}$, ya no será llevada a cabo por un medio $\mathrm{Y}$, sino por uno Z. Sí, como se aseveró anteriormente, un medio es necesario porque ningún otro puede llevar a cabo la acción de la manera que este la desarrolla, un cambio de medio implica una transformación en cómo se desarrolla la acción, aunque su finalidad sea la misma. Aquí se busca analizar cómo se desarrolla esta transformación en las narraciones sobre la violencia acaecida en Colombia durante los años 1980, propiciada por la guerra entre carteles de la droga, Estado y guerrillas.

Desde los años noventa existió en Colombia un interés creciente por los hechos que ocurrieron durante la guerra contra el narcotráfico. Si bien muchos libros y películas fueron creadas, ninguna logró, a mi parecer, la fuerza e impacto como $\mathrm{La}$ parábola de Pablo: auge y caída de un gran capo colombiano, de Alonso Salazar (2001). El hecho de este éxito llevó a la cadena de televisión, también colombiana, Caracol Televisión. a transferir la narración escrita a una telenovela titulada el Patrón del mal. Esta serie logró tal éxito, que la cadena internacional de contenidos web Netflix decidió desarrollar una 
versión, bastante desfasada en cuanto al contenido se refiere, para el streaming llamada Narcos.

La primera transformación medial que se desarrolla es aquella desde la oralidad hacia la escrituralidad. Alonso Salazar, en una investigación de cinco años, recoge los testimonios de las personas cercanas a Escobar que siguen vivas, así como a sus enemigos y víctimas. De esta manera, a partir del personaje ficticio "Arcángel", Salazar adelanta un proceso que implica una transformación radical de la historia de Pablo Escobar, a saber, la organiza. Este aspecto de la escrituralidad, que si bien no es nuevo, sigue llamando la atención porque termina por imponerse sobre la oralidad. La historia del capo es difícil de rastrear, primero, porque su negocio era ilegal, lo cual hace que gran parte de otro material, que no sea oral, sea escaso. Segundo, el hecho de que la red de Escobar fuera tan grande. Existen testimonios tan disímiles que llegan a ser contradictorios, como el del sicario John Jairo Velásquez y el hijo de Escobar. ${ }^{1}$ Así, es necesario de alguna manera direccionar todos esos testimonios en busca de la coherencia, dejando de lado una comprobación sobre la veracidad de los testimonios. Este ejercicio hecho por Salazar, se vuelve unos de los primeros registros escritos sobre la vida de Escobar, que es irremediablemente gran parte de la historia colombiana. De esta manera, se convierte también en el primer archivo que da cuenta de una historia más o menos completa, que se puede conseguir en un solo objeto.

La escrituralidad finalmente transforma la oralidad en algo que es accesible en cada momento y conserva las mismas características de cuando se accedió por primera vez. Este hecho no es posible con la oralidad, ya que cada nuevo contar, aunque sea el mismo testimonio, siempre será diferente. La entonación, la organización de los hechos, los nombres, etc., siempre serán diferentes en un segundo contar. En este sentido, la oralidad está anclada al presente. El contar siempre será ahora y de esta manera, se hace imposible una repetición, porque

1 Se puede comparar la visión sobre Pablo Escobar en los productos audiovisuales Los pecados de mi padre (Entel, 2009) y la serie de Caracol Televisión Sobreviviendo a Escobar: Alias J.J. (Aguilar, 2017). una repetición de la narración será un distinto contar. Esta barrera del presentismo es sobrepasada por el libro. En este, el contenido se mantiene intacto, lo único que cambiará, será la interpretación de los sujetos, lo cual le dará un nuevo estatus. No obstante, esta ventaja de grabación del libro implica una pérdida gigantesca de la experiencia que se transcribe. El dolor, la alegría, la pasión o la rabia con que los eventos son contados al ser rememorados se pierden. Es posible que el autor nos transmita dolor a través del libro, pero nunca se igualará a la intensidad del hecho mismo o al testimonio de aquel que lo experimentó. De la misma manera, el libro no tiene gradaciones de exclamación, ni pausas, ni ese desorden del testimonio que siempre da espacio a una nueva rememoración o pregunta.

De este esfuerzo del escritor colombiano, por dar sentido a la historia de Pablo Escobar, se llega a una telenovela que se basa en el libro. El patrón del mal, título de la telenovela, sigue la línea argumentativa del libro de Salazar, no obstante, la narración es modificada porque ella se transmite en un medio distinto. El primer cambio que se desarrolla es la aparición de rostros, cuerpos en movimiento y escenarios, que el libro solo nos proporciona en pocas páginas a través de portadas de periódicos. Si bien este hecho no presenta nada novedoso, ya que cada programa de televisión hace lo mismo, sí pone de manifiesto una lógica que funciona de manera distinta. Aunque la escritura permite la descripción de hechos que suceden de manera paralela, la lógica del libro sigue siendo analítica. Es decir, una descripción se sigue después de otra por medio de conectores y transiciones como: $\sin$ embargo, no obstante, a continuación o con un espacio en blanco que significa una pausa. La televisión, por el contrario, hereda una lógica de la oralidad que posee otro tipo de conectores que se dan de manera sincrónica. Los gestos, los tonos de la voz, la proxémica o la kinésica introducen nuevos conectores que producen una lógica distinta de la sucesividad de la escrituralidad (Henríquez, 2009). Este cambio de lógica lleva a que la telenovela posea un horizonte distinto de interpretación y la posibilidad de memorizar un significado con una característica 
del significante que estableció el programa televisivo. Se hace entonces necesaria la puesta en marcha de otras categorías epistemológicas que ya no trabajan a través de unidades que se sintetizan, sino a través de sincronías que se sintetizan. Esto que en principio parece ser una desventaja, en cuanto la información recibida no es analizada en detalle, se puede ver como una ventaja por la posibilidad de agregarle nuevos horizontes de interpretación a la narración. Salazar, por ejemplo, narra los hechos de cuando La Violencia, periodo de guerra entre los partidarios del partido liberal y conservador por la muerte del caudillo Jorge Eliécer Gaitán, alcanza a la familia Escobar Gaviria de la siguiente manera:

En plena Violencia, a doña Hermilda la trasladaron a ejercer de maestra a una vereda del lejano municipio de Titiribí. Se instaló con su esposo y sus hijos en la casa anexa a la escuela. La chusma de godos -como les decían a los conservadores- no soportó que una maestra liberal, como Hermilda Gaviria, supuestamente portadora de espíritus masónicos e impíos, educara a los hijos de la vereda, y rodeó la escuela. Al sentir el estruendo y la amenaza de la muerte, doña Hermilda, Abelito, Roberto, Pablo y los demás hijos, como única defensa, se subieron a la cama y abrazados le rezaron al Niño Jesús de Atocha:

\footnotetext{
Glorioso Niño de Atocha, astro divino de excelsa majestad, te saludo y adoro y te suplico me dispenses tu clemencia en memoria del inefable gozo que sintió tu Santísima Madre cuando te recibió en sus brazos y cuando los coros angélicos entonaron jubilosamente por todos los ámbitos las dulces armonías del Gloria in Excelsis Deo, en señal de alabanza al Todopoderoso por tu venida al mundo para bien del humano linaje
}

La fe al Niño de Atocha doña Hermilda la había aprendido de su abuela, quien se le encomendaba para todo. Y en este momento crucial, Él de nuevo la ayudó. La chusma intentó incendiar la casa pero las maderas no prendieron, intentó tumbar las puertas pero el Niño convirtió la frágil casa en un búnker. Los guardó hasta que el Ejército los rescató en las horas de la madrugada. Al salir vieron algo que no habrían de olvidar nunca: campesinos liberales de la vereda habían sido colgados por los pies de las vigas de la escuela y decapitados con machete. La sangre, oscura y espesa, cubría el corredor y se pegó a sus pies. El Ejército les recomendó huir de inmediato, sin recoger siquiera la ropa, y los escoltó unas dos horas hasta llegar al pueblo, de donde siguieron solos el camino hasta el tren que los llevaría de nuevo a Medellín. (p. 30).

Esta descripción bastante detallada de la situación provee información importante que la telenovela no ofrece, como lo son la razón por la cual los querían masacrar y quiénes lo querían hacer y el motivo por el cual esa escena nunca sería olvidada por Pablo Escobar y su familia. No obstante, este evento se hace mucho más vívido a través de la recreación hecha por la telenovela. La imagen de hombres colgados (figura 1), los disparos ${ }^{2}$ y los gritos de desesperación producen en el televidente un sentimiento de angustia más parecido al que vivieron los implicados que la lectura analítica del libro. Si a esto le agregamos un nuevo ingrediente, herencia de las radionovelas (Martín-Barbero, 2003), que es la música, el proceso de producción y re-presentación que se hace de la escena se va cargando de un significado diferente. Observamos que existe un gran número de conectores de significantes que, si bien corresponden a un mismo hecho comunicativo, la fuerte impresión que tuvieron los Escobar de ese día, estos le agregan nuevos significados que van más allá de las palabras. Allí dónde estas encuentran su límite, nuevos elementos empiezan a darle significantes a esos significados que las palabras no cubren.

Esta lógica que ya era existente en la oralidad, se muestra nuevamente reveladora con la aparición del video. A la lógica que impuso la escrituralidad de una función tras otra, el video impone múltiples funciones lógicas en un mismo instante. La escrituralidad busca síntesis; el video, sincronización. Esto lleva a un segundo cambio que se introduce al transferir un contenido del libro al video. Debido a que la lógica del libro se basa en palabras que van unas tras

2 La escena completa se puede acceder con el siguiente enlace desde el minuto 9:30 hasta al 12:00: https://www.youtube.com/wat ch?v=pylto493Zxg\&list=PLYy9uFgc6ad8RGHYH1hAjlo5lm44kwjks 
otras, el tiempo de lectura es de, por sí, subjetivo. Si bien existen estándares de cuántas palabras debería leer un sujeto en un minuto y un tiempo determinado para entender dichas palabras, el tiempo de lectura, a menos que sea una lectura pública, está determinado por la lectura del sujeto que la lee. Esto parece ser obvio, sin embargo, si lo comparamos con la televisión o el videostreaming nos lleva a un cambio de temporalidades que produce la diferencia entre las lógicas del libro y el video. El sociólogo alemán Niklas Luhmann desarrolla una distinción entre experiencia y acción. Haciendo referencia a la teoría fenomenológica de Edmund Husserl (1985) en su tomo X, Luhmann define la experiencia como "la experiencia propia accesible a través del proceso de conciencia en tanto que la selectividad de esta no se le atribuye al sistema seleccionado, sino al medio ambiente" (Luhmann, 1972, p. 93). Es decir, la temporalidad de la experiencia depende en ese momento únicamente de la conciencia que se relaciona con el mundo. Ningún sistema interfiere, ralentiza o acelera la experiencia. La lectura dura lo que tiene que durar. Por el contrario, el video es desde su lógica sincronizado. No es posible que los cuerpos aparezcan antes de que suene la música o en un escenario anterior. Esto produciría el colapso total del significado de la escena. Así, los elementos de la escena se sincronizan a partir del medio actual dominante para la sincronización, a saber, el reloj. La escena en que los Escobar son perseguidos comienza en el minuto 9:30 del capítulo 1 y termina en el 12:00. No existe posibilidad de ampliarlo, ni de reducirlo. La experiencia está cronológicamente medida y todo televidente debe, si lo puede hacer, interpretar las escenas en el tiempo dado. En este sentido, la televisión impone un tiempo y un ritmo al espectador. Esto no sucede simplemente por los horarios que impone para ver dicho programa o debido a la elección de la duración de los comerciales. La lógica misma del video impone al espectador un tiempo que no puede ser franqueable.

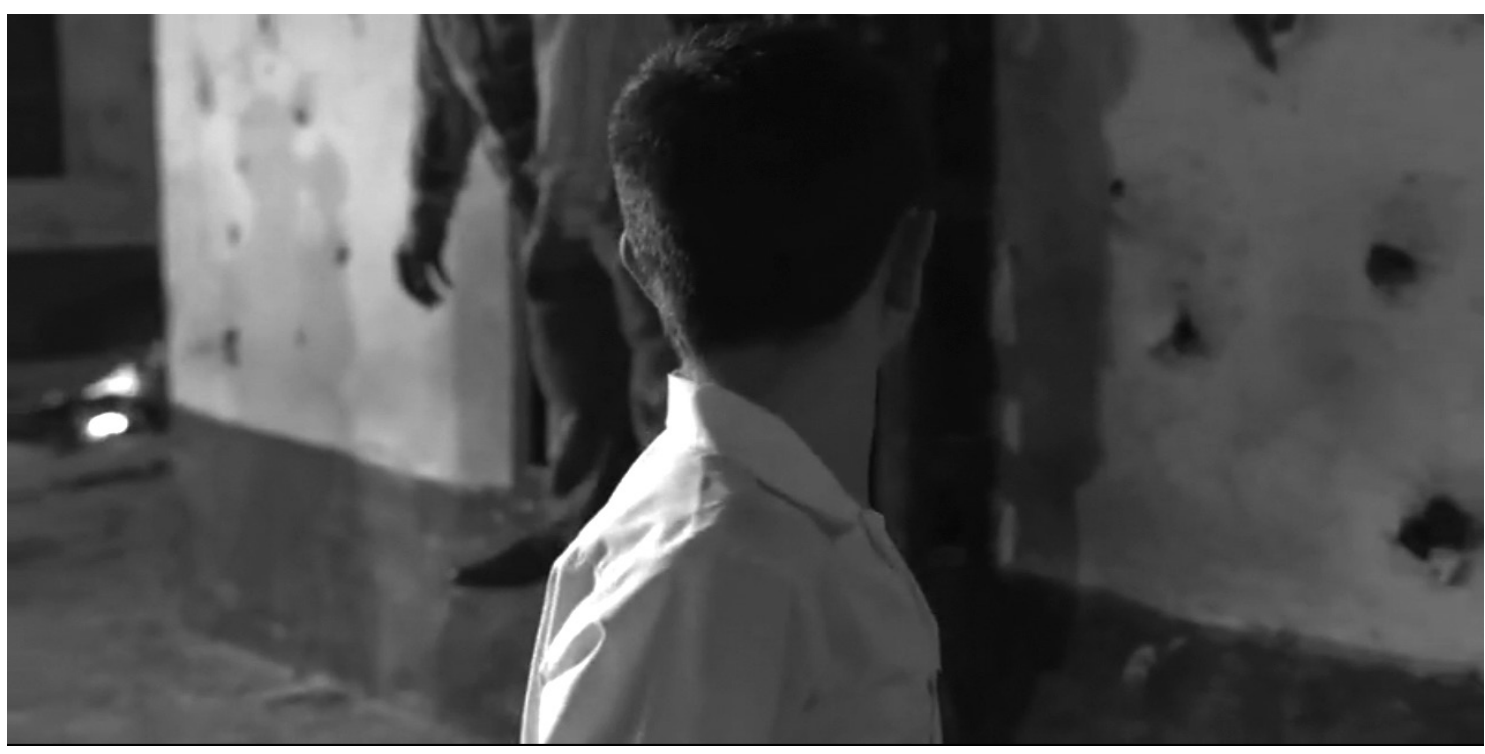

Figura 1. Familia Escobar huyendo.

Fuente: tomado de la telenovela El patrón del mal, capítulo 1. 
Husserl distingue entre retención, protensión, recuerdo y expectativa. La retención es definida por él como "un sencillo ahora, primera recordación" (1985, p. 31). El proceso de rememoración se diferencia del de retención en cuanto el primero se dirige a una unidad de percepción que "en una mirada objetiva aparece esta [unidad] ya no más como 'presente', sino como 'pasado'. [La totalidad], sin embargo, aparece como presente, en cuanto aún es [percibida]" (Husserl, 1985, p. 38). Así, se distingue aquello que es pasado en cuanto el recuerdo de lo experimentado inmediatamente, pero de lo cual, sin embargo, aún no tengo el sentido completo. De la misma manera, la protensión se diferencia de la expectativa, en cuanto la protención es la espera de la siguiente unidad de percepción, mientras la expectativa es la espera de que un hecho o comunicación se produzca de una determinada manera. Está distinción es importante para observar la diferencia entre la lógica de la escritura y la del video. La protensión de la experiencia de lectura se relaciona solo a palabras. Espero una palabra más, hasta que el sentido se haya dado. En el video, al mismo tiempo, se configura un tono, una palabra, un gesto, los cuales están a la espera de otro tono, otra palabra, otro gesto. Esto obliga a estos hechos a compartir un mismo instante, a la espera de los próximos que compartirán a la vez un mismo instante. Solo es la rememoración o la expectativa las que pueden separarlos en la fantasía. De allí que el video fuerce a su comprensión en un solo ritmo. Uno que fue marcado previamente.

Este hecho de la configuración previa del tiempo se vincula a su vez con la historia misma de la conciencia temporal humana. Desde la implementación de la disciplina del reloj en los monasterios medievales (Müller, 2015), la vida moderna se ha ceñido a la disciplina del reloj. De esta manera, el video sucumbe también a este régimen, y se exige un número de fotogramas por segundo. He allí la complejidad de la lógica del video. Por un lado, permite una interpretación más amplia y vivaz de un hecho comunicativo, no obstante, nos imprime una disciplinización de la percepción.
Esta disciplinización de la percepción no es implementada solo a través de experimentar el video. El uso, por parte de las compañías televisivas, establece también tiempos de percepción e interpretación. Si, como afirmo Husserl, la dación de sentido solo se da cuando la experiencia acabe, durante el desarrollo de una acción que dure mucho tiempo, las pausas desempeñan un rol importante. Estas serán importantes porque determinarán hasta que segmento la experiencia debe ser temporalmente comprendida, para luego comenzar un proceso de imaginar y crear expectativas que serán contrastadas con lo mostrado para establecer, finalmente, una nueva interpretación.

Allí radicará la diferencia entre El patrón del mal y Narcos. La telenovela aún responde a las dinámicas de la televisión privada abierta a las grandes masas. Por tanto, esta aún obtiene sus ganancias a partir de las pautas comerciales. Eso la obliga a desarrollar pausas que determinan el significado del segmento dado. Durante las pausas comerciales, el espectador comenzará a crear expectativas sobre lo que puede o no suceder en el próximo segmento. Así mismo, se hace una idea de lo que ha pasado por medio del proceso de rememoración. Todo esto sin que el sujeto pueda cambiar el ritmo de la presentación. Lo máximo que pueda hacer es obviar las pausas comerciales y dirigirse a otro tipo de cosas. Lo que no es más que otro tipo de pausa. La serie de Netflix, por el contrario, ofrece el capítulo completo, y muchas veces, la temporada completa. La interpretación que surgirá será la totalidad del hecho comunicativo. La repetición por parte del sujeto a través de su computadora, algo parecido a lo que sucede con el libro, lo cual permitirá a su vez nuevas interpretaciones en cuanto permite acceder a elementos que, debido a la sincronización de elementos en el video, no pudieron ser percatados por el sujeto en una primera o segunda observación.

\section{Función, públicos y genealogías}

Hasta este momento, solo me he dirigido a las diferencias puramente mediales de las narraciones sobre los narcos en Colombia. Ahora, dirigiré mi mirada al contenido de las narraciones. Si bien estas dependen 
del medio en que son transmitidas, el contenido es normalmente mucho más controlado por aquellos que crean la narración. Así, la narración deja entrever mucho más aquello que se está buscando representar ${ }^{3}$ social, cultural y económicamente. En este sentido me referiré a tres aspectos que son contrastantes entre las tres narraciones. La mayoría de estos contrastes se referirán a la serie Narcos y a la telenovela El patrón del mal. Esto se debe a que la última se basa en el libro de Alonso Salazar y sigue un guion casi igual al del libro.

\section{Función}

Si bien el libro y la telenovela se enmarcan en la industria cultural, su objetivo, sin entrar a la discusión de si lo lograron o no, es producir un espacio de memoria y reflexión sobre lo sucedido durante las décadas de 1970 y 1980 en Colombia, debido al acenso vertiginoso del narcotráfico. Esto se puede rastrear fácilmente en el final del libro y el comienzo de cada capítulo de la telenovela. Escribe Salazar: “¿Qué significaría la muerte de Pablo Escobar? Y sobre todo recuerda su respuesta: ¡nada! ¡Absolutamente nada, todo seguirá como antes!” (Salazar, 2001, p. 2001). Allí el escritor colombiano se pregunta, por medio de su personaje ficticio Arcángel, ¿qué significo la muerte del gran capo? Su respuesta "absolutamente nada", no afirma que Medellín y Colombia no hayan cambiado con la vida y la muerte de Escobar. Más bien se refiere a que las condiciones que lo produjeron no variaron, que el país que produjo los narcos no ha cambiado sus condiciones sociales. Así, una reflexión de los hechos es necesaria, para establecer que hay más allá del gran monstruo llamado Pablo Escobar.

La telenovela, por su parte, ya señala aquello que busca a través de la canción la "Última bala", de Yuri Buenaventura (2012), la cual suena al principio de cada capítulo:

Vendrán terremotos, corruptos y mafiosos Hombres o mujeres ya no hay miedosos

3 Esto no implica que la narración llega clara y directamente al sujeto. Solo se afirma que los creadores de la narración imprimen unas visiones culturales, económicas y sociales.
Mucha plata repartiste por los barrios

Convertiste a mis hermanos en sicarios

Que esta historia no se borre de tu mente

En honor a nuestros muertos que cayeron vilmente

Se mata la gente, pero no las almas

Mi patria no cae, tropieza o resbala

Se pone de pie, se limpia la cara

La letra de la canción ya muestra la función que quiere cumplir la telenovela. Con la frase "que esta historia no se borre de tu mente en honor a nuestros muertos que cayeron vilmente", se observa la función de memoria que quiere cumplir el programa televisivo. Por otro lado, si bien Narcos en su intro muestra imágenes reales de lo sucedido en ese tiempo (la toma del palacio, la explosión de un carro-bomba en las instalaciones del DAS, etc.), estas imágenes son presentadas con la canción "Tuyo", de Rodrigo Amarante, ${ }^{4}$ de fondo. Esta canción es de género romántico. Esto nos empieza a desvelar la función de la serie que está entre contar una historia para el disfrute y hacer una descripción, de por sí errada, de lo sucedido con los capos del narcotráfico.

Además de la canción y las imágenes en el intro, al final de estas secuencias se muestra un recuadro con una frase. En el Patrón del mal, la frase que aparece es: "el que no conoce su historia, está obligado a repetirla". Mientras tanto, Narcos hace referencia al realismo mágico como explicación para entender el surgimiento de un criminal como Pablo Escobar con la siguiente frase: "el realismo mágico es definido como aquello que ocurre cuando una configuración altamente detallada y realista es invadida por algo demasiado extraño para creer". Esto nos lleva a nuestra segunda distinción, a saber, a qué público se refieren.

\section{Públicos}

Desde los cabezotes, como se afirmó anteriormente, ya es claro el público al que se dirigen. En El patrón del mal no es necesario afirmar que el hecho del surgimiento de este criminal, que casi se vuelve mito, se enmarque en el realismo mágico, por cuanto la serie

4 La canción se puede encontrar en el siguiente enlace https://www. youtube.com/watch?v=PtJ6yAGjsls. 
tiene como función crear memoria dentro de dicha población. De allí que se explique, tanto en el libro como en la telenovela, el surgimiento, auge y caída del capo de Antioquia a partir de los colombianos mismos. La aparición de extranjeros que cumplan un rol determinante es mínima, sino inexistente. En el libro, Arcángel es aquel que interpreta el papel de narrador. Un sicario ficticio que mezcla los distintos puntos de vista de los que vivieron esa época. La telenovela prescinde de un narrador en cuanto la lógica de la historia se desarrolla a partir de los diferentes elementos que se despliegan en el video, los cuales dejan entrever la poca injerencia directa, fuera de la política antidroga de Estados Unidos, de los extranjeros en el problema.

Narcos, por su parte, presenta un narrador que es Steve Murphy, un agente de la DEA que cumple un rol vital en la captura de Pablo Escobar. Esto se suma a la ya mencionada entrada de cada capítulo en la serie que revela a qué público se dirige la serie, a saber, a alguien que quiere que se le describa una historia, pero que no está buscando reconstruir la historia más o menos como sucedió y que no tiene un horizonte previo de interpretación sobre lo sucedido en Colombia en esos años.

Este direccionamiento a los públicos se debe cumplir desde dos parámetros: la tradición cultural audiovisual y un acoplamiento entre la lógica de narración que crea el producto audiovisual y la que posee el sujeto previamente sobre la historia. En Colombia se han desarrollado varios géneros audiovisuales, no obstante, el de mayor acogida ha sido la telenovela. Esta se caracteriza por el uso constante y casi omnipresente de música, la cual determina hacía dónde se dirige la acción: suspenso, comedia, drama, etc. Así mismo, contiene un alto contenido melodramático donde las emociones son fundamentales. Solo a través de estas emociones que conectan y fundamentan las acciones de los personajes, las acciones cobran sentido para el espectador. Son esas relaciones afectivas las que llevan al espectador a crear empatía o no con dicho personaje. Si no se entiende esto, no se pueden entender los profundos dilemas morales que están en juego cuando un per- sonaje se ve llevado a tomar una decisión forzosa. Además, la duración y transmisión de la telenovela hacen que los personajes puedan ser desarrollados a profundidad, por tanto, no sería aceptable para el público la aparición de un personaje vital en la historia en un solo capítulo.

Narcos, por su formato de 60 minutos por capítulo, no desarrolla una gran cantidad de personajes a detalle, sino que los incluye en un capítulo y allí mismo desaparecen. Esto se debe al número de episodios que tiene cada producto audiovisual para desarrollar la historia. Mientras Narcos desarrolla la serie en 20 episodios, la telenovela lo hace en 113. Así mismo, el formato de la serie, hace que la música casi no aparezca. Finalmente, introduce una cantidad de variaciones visuales para adaptarse a un tipo de público. Los personajes en El patrón del mal pueden parecer chabacanos y pintorescos, sin embargo, tienen mucho más parecido y muestran las raíces populares, sin los cuales la vida de los capos de los ochenta no es entendible. Esto se presenta en contraste a los personajes mucho más estilizados que se muestran en Narcos.

El segundo aspecto es el acoplamiento de lógicas narrativas. Para que la narración se mantenga, esta debe ser creíble. Si bien son narraciones ficticias, el espectador debe darle un cierto grado de realismo o credibilidad. Debe aceptar que la narración se ajusta a una historia lógica y no por medio de arbitrariedades. Esta dación de coherencia y realidad, no obstante, muchas veces no depende de la historia misma, cuando esta se refiere a hechos reales o a productos transmedializados. Si el espectador conoce el contexto que precede y sirve de trasfondo de la narración, este debe encontrar que la lógica de narración se adecua en gran medida a lo ya conocido por él. Si, por ejemplo, el espectador sabe que un personaje tenía una apariencia distinta a la mostrada en el video, este lo va encontrar demasiado ficticio. Así, no podrá desarrollar esa creencia de lógica necesaria para mantener la narración expectante. En este sentido la lógica narrativa de Narcos se relaciona a un público que carece casi totalmente de lo acontecido en Colombia en esa época, en comparación con la 
telenovela que se dirige a un público que vivió esa época o le fue contada por sus padres. Esto lo ejemplificaré con la tercera distinción: la genealogía del narcotráfico en Colombia en ambas series.

\section{Genealogía del narcotráfico}

Lo más llamativo del contraste entre el libro, la telenovela y la serie, es la profunda diferencia del último con los primeros en cuanto a un tema fundamental, a saber, cómo se originó el narcotráfico en Colombia.

El primer hecho llamativo es la agencia de Colombia en la creación del negocio ilegal. Narcos nos dice en el primer capítulo que Reagan, elegido por muchos estadounidenses, decide apoyar a Pinochet en Chile. Este decide atacar el tráfico de cocaína que se está dando en el país austral. De esta arremetida, la Cucaracha, traficante chileno, huye y decide ir a proponer el negocio a los colombianos que eran expertos contrabandistas. En la telenovela, como en el libro, el hecho quiere ser explicado desde Colombia mismo. Si bien Escobar era contrabandista, el negocio del tráfico de drogas lo precedía. Tanto los Ochoa como la famosa Viuda Negra participaron previamente en el negocio de la cocaína y son los que inician a Escobar. En esto no existe ninguna injerencia de alguna fuerza extranjera. Si aceptamos el trabajo de Salazar como de los pocos serios, encargado de documentar la vida de Pablo Escobar, lo que se presenta en la serie Narcos es un desfase tan grande con la realidad, que aquel que conozca la historia ya no podrá crear esa comunión de lógica necesaria para que la historia se imagine verosímil.

Además de esto, no deja de ser llamativo que, en una serie narrada por un agente de la DEA, quien finalmente cumple un rol esencial en la captura de Escobar, toda la agencia del problema y la solución recaiga en Estados Unidos. De esta manera, Colombia ni crea ni soluciona sus problemas y se presenta más bien como un apéndice de Estados Unidos.
La segunda gran diferencia se da en una imagen que Narcos copió visualmente de las telenovelas, pero le da un significado distinto. En aquella famosa escena en el puente, cuando viajaban con un número grande camiones de contrabando, Escobar muestra su temperamento como criminal en ambos productos audiovisuales. Sin embargo, hay una gran diferencia. En El patrón del mal, Escobar empieza a mostrar su temperamento, pero él es hasta ese momento solo un peón en el mundo criminal. En la serie Narcos, ya se le presenta como el dueño de Antioquia y con esa aura que solo se le va a agregar en los últimos años en los barrios populares de Medellín. Esta diferencia remarca nuevamente el alto grado ficticio de Narcos. Para esa época, Escobar era un criminal de poca monta que no tenía el inmenso poder que se le quiere agregar.

Estas dos diferencias genealógicas hacen que las historias cobren un significado distinto. Sin embargo, para aquellos que vivieron la historia, la serie "Narcos" solo es un producto que nuevamente quiere explicar las dinámicas internas con reducciones simplistas, que evitan la complejidad del problema. De nuevo, hay un deseo por explotar una historia que parece increíble, pero que carece de una lógica para aquellos que conocen lo mucho o poco que se ha desentrañado de esa época oscura y terrible de la historia colombiana. La historia se vuelve inverosímil para quienes ya conocen el contexto, si estos no son conscientes de la intención de los autores. Es decir, si el público es consciente de que la intención de los autores es desarrollar una lógica distinta a aquella que relacionan con los hechos reales, ${ }^{5}$ no debería crearse ninguna ruptura en esa comunión lógica de la serie o telenovela/ espectador. Se crea un pacto con el autor para entender que ese mundo tiene una lógica distinta. Siempre y cuando esta se siga, la historia será verosímil y dicha comunión continuará. Por el contario, si el público está esperando una historia de la vida real, se creará una ruptura.

5 Se obvia por motivos de espacio la discusión sobre lo real. 


\section{Conclusiones}

El presente artículo analiza la manera en que el proceso de transmedialización se desarrolla en el caso de las narrativas construidas alrededor de Pablo Escobar y el fenómeno del narcotráfico en los años setenta y ochenta en Colombia. Con ello se señalan las diferentes transformaciones que aparecen desde la oralidad al streaming. Para ello, el artículo aborda dicho fenómeno desde dos perspectivas: la primera, desde las transformaciones puramente mediales; la segunda, de cómo estas transformaciones afectan los discursos y los modos de circulación de los productos mediales. Desde la primera postura, dichas transformaciones son históricas y cambian las condiciones tanto perceptivas como epistemológicas. Cabe recalcar entre ellas la aparición de una epistemología fuertemente ligada a lo analítico por parte de la escritura, mientras lo audiovisual se fundamenta en la sincronía. Ello produce dos maneras distintas de conocer el mundo. Así mismo, cada medio produce un régimen temporal determinado que se inclina hacía el presente o el pasado.

Finalmente, desde la segunda perspectiva se muestra cómo, debido a las dinámicas propias del streaming, contenidos que se desarrollaban para púbicos nacionales o regionales se convierten en productos internacionales que varían el sentido de la narrativa. No solo desde la transformación radical de la historia contada, sino desde cómo se cuenta la historia. Nuevos géneros, con tiempos mucho más acelerados en la ocurrencia de las acciones contadas, son las principales transformaciones que la mudanza de medios implica.

\section{Referencias}

Aguilar, A. (productor) (2017). Sobreviviendo a Escobar: Alias J.J. [Serie de televisión]. Caracol Televisión.

Bernard, Carlo, Brancato, Chris y Doug, Miro (directores y productores) (2015). Narcos. Netflix.

Buenaventura, Y. (Compositor). (2012). La última bala. Caracol Televisión.

Entel, N. (director) (2009). Los pecados de mi padre. [Documental]. Argentina/Colombia: Arko Vision.

Henríquez, P. (2009). Oralidad y escritura en el teatro indígena prehispánico. Estudios Filológicos, 44, 81-92.

Husserl, E. (1985). Texte zur Phänomenologie des inneren Zeitbewusstseins. (Bernet, Rudolf, Ed.). Hamburg: Meiner.

Krämer, S. (1998). Medien, Computer, Realität. Wirklichkeitsvorstellungen und neue Medien. Berlín: Suhrkamp.

Luhmann, N. (1972). Weltzeit und Systemgeschichte : über Beziehungen zwischen Zeithorizonten und sozialen Strukturen gesellschaftlicher Systeme. En Soziologie und Sozialgeschichte: Aspekte und Probleme (pp. 81-115). Opladen: Westdt. Verl.

Martín-Barbero, J. (2003). De los medios a las mediaciones. (5a. ed.) Bogotá: Convenio Andrés Bello.

Moreno, C. y Mora, L. (directores) (2012). El patrón del mal. [Serie de televisión]. Bogotá: Caracol Televisión.

Müller, P.V. (2015). "Kloster auf Zeit" im Wandel der Zeiten. Praxis Gemeindepädagogik, 1/2015.

Salazar, A. (2001). La parábola de Pablo: auge y caída de un gran capo colombiano. Bogotá: Editorial Planeta. 